\title{
La trans-formación del Derecho: La evolución del Derecho Internacional de los Derechos Humanos para proteger la identidad de género de las personas trans ${ }^{(*)(*)}$
}

\author{
The trans-formation of Law: The evolution of the international human rights \\ law in order to protect the gender identity of transgender people
}

\author{
Adrián Lengua Parra ${ }^{(* \star)}$ \\ Perú - Pontificia Universidad Católica del Perú
}

\begin{abstract}
Resumen: El presente texto busca describir el proceso de reconocimiento de la identidad de género como motivo prohibido de discriminación en el Derecho Internacional de los Derechos Humanos (en adelante, DIDH) y mostrar cómo ello ha permitido una mejor protección de los derechos de las personas trans. Para tal fin, se realiza una clasificación de los discursos que han abordado la situación de dichas personas y su relación con el Derecho. En base a dicho marco teórico, se postula que el DIDH ha acogido un modelo que busca la despatologización de las identidades trans y se explica cuál es el estándar actual que deben cumplir los Estados para proteger el derecho a la identidad de dicha población.
\end{abstract}

Palabras clave: Derechos Humanos - Identidad de Género - Personas Trans - Igualdad y No Discriminación

\begin{abstract}
The present paper seeks to describe the process of recognition of gender identity as a prohibited reason for discrimination in International Human Rights Law (hereafter, IHRL) and show how this has allowed a better protection of the rights of trans people. For it, this document realizes a classification of the speeches that have addressed the situation of these people and their relationship with the law. On this basis, it is postulated that the IHRL have supported a model that seeks the depathologization of trans identities and it is explained which the actual protection standard that States must comply in order to protect the right of identity of that population.
\end{abstract}

Keywords: Human Rights - Gender Identity - Trans Persons - Equality and Nondiscrimination

$\left(^{*}\right) \quad$ Nota del Editor: este artículo fue recibido el 2 de octubre de 2019 y su publicación fue aprobada el 11 de noviembre de 2019.

$\left({ }^{* *}\right) \quad$ El presente artículo está basado en los capítulos I y III de mi tesis de licenciatura para obtener el título de abogado.

${ }^{* * *}$ ) Abogado por la Pontificia Universidad Católica del Perú (PUCP) y candidato a LLM en Georgetown University. Consultor jurídico de la Secretaria de Peticiones y Casos de la Comisión Interamericana de Derechos Humanos (CIDH). Las opiniones vertidas en este artículo son atribuibles únicamente al autor y no representan, necesariamente, una posición de la CIDH. Miembro extraordinario de lus et Veritas. Contacto: a.lengua@pucp.pe. 


\section{Introducción}

Históricamente las personas trans han sufrido diversas prácticas de exclusión que las han colocado en una grave situación de vulnerabilidad. La prevalencia de una concepción binaria y determinista sobre el sexo que únicamente analiza la composición de nuestros órganos genitales para calificarnos como hombres o mujeres ha consolidado un sistema regularizador que excluye a las personas que no se adaptan al mismo. Utilizando los términos de la antropóloga Gayle Rubin (1989), se puede apreciar cómo determinadas ideologías han construido un sistema de poder que define las condiciones de privilegios y desigualdades de las personas en base a un sistema jerárquico de valor sexual.

En el caso de las personas trans, este sistema de jerarquía ha sido explicado bajo el término de cisnormatividad (utilizando "cis" como antónimo del prefijo "trans"). Al respecto, la Comisión Interamericana de Derechos Humanos (en adelante, CIDH) precisa que dicho concepto "ha sido usado para describir la expectativa de que todas las personas son cisexuales (o cisgénero); es decir, que aquellas personas a las que se les asignó masculino al nacer siempre crecen para ser hombres y aquellas a las que se les asignó femenino al nacer siempre crecen para ser mujeres" (2015, pág. 41). Como muestran los informes del Alto Comisionado de las Naciones Unidas para los Derechos Humanos (en adelante, ACNUDH) (2011 y 2015), la permanencia de la cisnormatividad conlleva a que las personas trans sufran constantes violaciones de sus derechos básicos, tales como a la salud, la educación, el trabajo, la identidad, la integridad, e incluso la vida.

Del conjunto de derechos mencionados, resulta de particular relevancia la vulneración del derecho a la identidad. Lejos de ser una afectación menor, las personas trans sufren graves cuadros de estrés y depresión al ver coaccionada su identidad de género por la imposición de categorías identitarias. Además, la falta de reconocimiento jurídico y social de dicho rasgo identitario expone a la población trans a sufrir actos de discriminación al momento de ingresar al ámbito laboral, realizar un trámite bancario, acceder a servicios de educación y salud, entre otros. En tal sentido, la adecuada tutela y reconocimiento del derecho a la identidad resulta la puerta de entrada para que puedan ejercer plenamente sus derechos humanos (Saldivia, 2017).

A pesar de ello, el Derecho funcionó durante muchos años exclusivamente como una herramienta cómplice del sistema cisnormativo, agravando las condiciones de opresión de las personas trans. Mediante leyes y decisiones jurisdiccionales se legitimó un discurso patologizante que, con aparentemente objetividad y precisión científica, calificaba a las identidades trans como "enfermas" o "anormales", promoviendo el rechazo de las demandas de rectificación de nombre y género en los documentos identitarios de dicha población.
Recién a partir de la década de los ochenta esta situación comenzó a cambiar progresiva y sustancialmente. Desde disciplinas como la antropología, la psicología y la biología se comenzaron a cuestionar las bases de la cisnormartividad. Mediante la aplicación de una perspectiva constructivista, se constató que la concepción binaria y determinista del sexo no responde a una base objetiva y neutral, sino a un parámetro cultural que busca fomentar la reproducción humana. En esta nueva óptica, el cuerpo ya no se presenta como un campo ajeno a las influencias culturales, pues se postula que la misma lectura de nuestras características biológicas ha estado condicionada por distintos discursos de poder. En tal sentido, si los criterios para asignar las categorías de "hombre" y "mujer" no parten de una base científica incuestionable y con el devenir del tiempo se han convertido en un obstáculo para lograr condiciones de vida dignas en perjuicio de un sector de la población, se propone la necesidad de repensar estas etiquetas para lograr sociedades más justas y equitativas.

Este cambio de paradigma respecto al sexo generó una importante transformación en la práctica jurídica. La información aportada por los estudios citados comenzó a ser acogida desde el Derecho, permitiendo la promulgación de importantes sentencias y documentos que protegen y reconocen los derechos humanos de las personas trans. En razón a ello, el presente artículo busca explicar cómo se ha producido dicho proceso de transformación en el campo específico del DIDH. Constataremos que, mientras en un primer momento las decisiones jurídicas rechazaron las pretensiones de reivindicación de las personas trans, producto de la preeminencia de un modelo de carácter médico, en la actualidad, el DIDH tutela la identidad de género como motivo prohibido de discriminación en base a un modelo de reconocimiento. A partir de ello, explicaremos cuál es el estándar de protección actual que deben cumplir los Estados para tutelar el derecho a la identidad de dicha población.

Para tal fin, dividiremos el presente trabajo en tres partes. En la primera sección, 
introduciremos los modelos que se han utilizado para comprender y tratar la situación de las personas trans. En la segunda parte, analizaremos la respuesta que ha tenido el Derecho sobre la base de cada modelo a partir de un examen histórico de las decisiones realizas por órganos y tribunales internacionales. Además, en este último punto demostraremos la importancia que ha tenido la inclusión de la identidad de género como motivo prohibido de discriminación para el pleno reconocimiento y protección de las identidades trans. Finalmente, en la tercera sección, explicaremos cuál es el estándar internacional que deben cumplir los Estados para reconocer adecuadamente la identidad de género de las personas trans. Para ello, haremos especial énfasis en la reciente Opinión Consultiva 24 de la Corte Interamericana de Derechos Humanos (en adelante, Corte IDH o Corte), además de otras decisiones emitidas por otros órganos y tribunales internacionales.

\section{Los modelos de comprensión de las identidades trans}

Las personas trans padecen, hasta la fecha, las consecuencias de un discurso que promueve su identificación como personas enfermas que requieren ser curadas para ser incluidas adecuadamente en sociedad. Tal idea prevaleció durante muchas décadas hasta la incursión de nuevas posiciones que permitieron comprender de forma más amplia la situación de dicha población. A efectos de diferenciar con claridad las características de cada una de estas visiones sobre las identidades trans proponemos dividirlas en dos modelos: el modelo médico y el modelo de reconocimiento.

\subsection{Las identidades trans como patologías: el modelo médico}

En este modelo las identidades trans son comprendidas únicamente bajo un esquema patológico. Se asume que sufren algún tipo de trastorno o desorden mental que no les permite desarrollarse adecuadamente en sociedad. En tal sentido, el problema central radica en la persona, dejando de lado el contexto social. Debido ello, el modelo médico propone como solución para el problema de exclusión que sufre la referida comunidad la curación o normalización obligatoria de sus integrantes por medio de terapias psicológicas o incluso operaciones de afirmación de género.

La consolidación de este paradigma se produjo con el reconocimiento de la "transexualidad" como trastorno mental en las principales clasificaciones diagnósticas. Primero, en el año 1973, con su inclusión en la Clasificación Internacional de las Enfermedades y Problemas Sanitarios Relacionados (en adelante, $\mathrm{CIE}$ ) que administra la Organización Mundial de la Salud (en adelante, OMS); y posteriormente en el año 1980 con su incorporación en el Manual de Diagnóstico y Estadística de Trastornos Mentales (en adelante, DMS), gestionado por la Asociación Psiquiátrica Americana.

Resulta importante destacar que la inclusión del transexualismo en estos instrumentos médicos no fue criticada desde sus inicios por los defensores de los derechos LGBTI. Por el contrario, como señala Mass (2017), muchos profesionales que trabajaban con personas trans vieron este reconocimiento como una puerta de entrada para alcanzar soluciones legales y sociales en su favor. La tipificación de la transexualidad como trastorno mental permitía fundamentar por qué los sistemas de seguridad social debían asumir el costo parcial o total de las terapias de modificación corporal. De este modo, un sector importante en la defensa de los derechos de la comunidad trans avaló en el pasado la respuesta del modelo médico y la centralización del problema de vulnerabilidad en las características de esta población y no en el entorno.

En cuanto a los fundamentos, este modelo se basa en una visión determinista y binaria sobre el sexo, que afirma que la identidad y expresión genérica de las personas depende exclusivamente de la conformación de los órganos sexuales de cada ser humano y únicamente dentro del binomio hombre o mujer (Hawkesworth, 1999). Por ende, las identidades que no se ajustan a este esquema son calificadas como antinaturales o distorsionadas.

Esta concepción del sexo predominó por muchos años en la academia. Ni el surgimiento de los conceptos de género e identidad de género lograron modificar esta situación. Por el contrario, su aparición en la academia producto de los estudios psiquiátricos de John Money y Robert Stoller en la década de los sesenta y setenta legitimó la respuesta de índole médico hacia las personas trans.

Como señala Millet (1995), Money concluyó en sus investigaciones que la identidad sexual de una persona no es un factor innato o instintivo que derive de los órganos sexuales del ser humano. Por el contrario, durante los primeros meses de vida de una persona no es posible encontrar diferencias psicosexuales basadas solamente en el sexo, sino que es recién con 
la adquisición e influencia del lenguaje que se comienzan a determinar algunas características de la identidad de una persona. Posteriormente, Stoller (1968) constató que la identidad genérica de las personas constituye la identidad primaria del ser humano y que se puede desarrollar de manera independiente al sexo biológico. Este descubrimiento lo llevó a diferenciar entre género y sexo, siendo el primero una dimensión psicológica y cultural del ser humano, mientras que el segundo está referido a los atributos biológicos de la persona. En base a ello, en el marco del XXIII Congreso Internacional de Psicoanálisis (1963), planteó el concepto de identidad de género para hacer referencia al proceso personal y vivencial que tiene toda persona para identificarse con un género, producto de la interacción social y la constatación de los estándares de género vigentes en una sociedad.

A partir de este acontecimiento, Molina (2000) explica que el género sería acogido y desarrollado por la literatura feminista como un concepto con tres usos diferentes: (i) como categoría analítica, (ii) como sistema de organización de relaciones sociales y (iii) como criterio de identificación. A pesar que los dos primeros usos del término permitieron que los movimientos feministas combatan y reivindiquen su situación de subordinación social (Lamas, 1986), el tercer empleo del concepto no tuvo el mismo efecto en la situación de las personas trans.

Sin duda el rechazo a la idea de una identificación natural de las personas con el sexo asignado al momento de su nacimiento permitió cuestionar la visión determinista propuesta por el modelo médico. No obstante, la permanencia de una lógica binaria y regularizadora del sexo provocó que los casos de falta de correspondencia entre atributos biológicos e identidad de género deban ser normalizados por medio de la medicina. No había margen para la "ambigüedad": o se intervenía el cuerpo para que guarde consonancia con la identidad de género o se trataba la psiquis en aras de guardar un balance con los atributos biológicos. La respuesta frente al problema de exclusión de las personas trans seguía recayendo en acciones médicas sobre las propias víctimas a fin de lograr su normalización.

De este modo, el esquema de división entre sexo y género siguió resultando útil para los fundamentos del modelo médico. La presunción del cuerpo como un campo natural y ajeno a la cultural siguió legitimando la visión patologizante de las identidades trans, al mantener la idea del sexo como un atributo predeterminado bajo un esquema necesariamente binario. Como señalan Maffia y Cabral (2003), bajo este orden de ideas no se "discute la realidad de las diferencias sexuales, sino la legitimidad de los estereotipos construidos por la sociedad sobre esas diferencias, como si el sexo constituyera una materialidad inapelable" (pág. 86).
2.2. Las identidades trans como sinónimo de diversidad: el modelo de reconocimiento Los postulados de este modelo contradicen directamente lo establecido por el paradigma anterior. Bajo este esquema, las identidades trans ya no son entendidas desde una óptica médica, sino que su presencia solo constata la diversidad propia de los seres humanos. Por ende, la situación de vulnerabilidad de la población trans no se debe a su identidad de género (dado que no se trata de una patología), sino a la falta de reconocimiento de esta característica por parte de la sociedad. El problema ya no recae en la persona víctima de la exclusión, sino en los discursos promovidos socialmente en perjuicio suyo. En razón a ello, la respuesta hacia el contexto de opresión que padecen las personas trans se orienta a la eliminación de las barreras que impiden su libre desarrollo en sociedad, mediante la revaloración de sus identidades y la transformación de los discursos que niegan sus derechos.

Este nuevo paradigma cuestiona la concepción de sexo empleada por el modelo médico al proponer que el ámbito del cuerpo no representa un dato objetivo y natural. Por el contrario, se postula que el sexo también representa un concepto construido socialmente que agrupa características biológicas de las personas en base a un paradigma cultural. Producto de ello, y no de la propia naturaleza, se estableció un sistema binario que nos divide entre "hombres" y "mujeres" en aras de promover la reproducción humana.

Esta concepción del sexo encuentra sustento en los estudios constructivistas iniciados en la década de los ochenta con la aparición de la obra Historia de la Sexualidad de Foucault (2014). La tesis central del citado autor es que tanto la sexualidad como el sexo son construidos por la cultura a partir de los discursos generados en una sociedad. No se trata de una característica asignada únicamente por la naturaleza, sino que lo que conocemos y entendemos como sexo también se erigió a partir de lo que se ha construido discursivamente como verdadero, mediante distintos métodos entre la población $n^{(1)}$. A partir de ello se posicionó una "verdad" relativa al

(1) Foucault plantea que la psiquiatría, la medicina y otras disciplinas lograron intervenir sobre nosotros mediante una práctica heredada 
sexo que, por un lado, conserva e incentiva una sexualidad económicamente útil y políticamente conservadora; y por otra parte expulsa las prácticas infecundas, placeres periféricos y actividades sexuales que no tienen la procreación como fin.

Gracias a la tesis de Foucault, desde distintas disciplinas se comenzó a postular el rol protagónico de la cultura en la conceptualización de nuestros cuerpos. Como señala Laqueur (1994), las recientes concepciones sobre el sexo no responden solamente a cambios de comprensión científica. En la construcción del sexo siempre se encuentran de por medio reglas culturales, en tanto la cronología de los avances o descubrimientos de la ciencia no se ajusta a los nuevos conceptos sobre dicho atributo en su conjunto. Prueba de ello es que la determinación de los órganos sexuales que no disfrutaban de nombre propio (por ejemplo, la vagina) y las diferencias corporales respondieron a una idea cultural preconcebida sobre el hombre y la mujer.

Sobre esta base, en la década de los noventa se iniciaron una serie de estudios críticos encabezados, entre otras personas, por la filósofa norteamericana Judith Butler. En su obra El género en disputa (2007), la autora criticó la clásica conceptualización del género únicamente bajo la dicotomía "femenino" y "masculino". Consideró que, si el género es un determinado significado cultural del cuerpo sexuado, entonces no hay motivos para creer que el género deba ser una respuesta mimética del sexo, por lo que tampoco existen razones para asegurar que solo deban existir dos géneros.

Estas premisas llevan a Butler a plantear que la noción de "sexo" fue construida bajo la idea de una "matriz heterosexual". Los mismos discursos que construyeron y regularon la heterosexualidad para favorecer las prácticas reproductivas entre los seres humanos, también regularon el concepto de sexo para que solamente existan dos categorías genéricas: hombre y mujer. El razonamiento es el siguiente: la constitución y promoción de una sexualidad económicamente útil (que permita la reproducción humana) requiere normalizar la conducta heterosexual, pero además presupone que existan dos sexos que se complementen en términos reproductivos. Dicha necesidad conllevó a que las características primordiales que diferencian a mujeres y hombres sean aquellas imprescindibles para dar vida una nueva persona.

Cabe precisar que mediante esta concepción Butler no cuestiona la existencia de ciertos rasgos biológicos que caracterizan a las personas o plantea una tesis "antirealista" que niegue la materialidad de ciertos atributos de las personas (Searle, 2014). El hecho de señalar que el cuerpo se encuentra construido histórica y culturalmente, no es sinónimo de afirmar que el cuerpo es solo y únicamente una construcción. Por el contrario, los postulados de este paradigma van orientados al concepto binario del sexo, buscando entender cómo los discursos históricos sobre la sexualidad y el cuerpo llevaron hasta este punto (Butler, 2016).

Producto de este razonamiento, Butler (2007) define los efectos del género sobre el cuerpo como un proceso performativo. En base a la teoría de John Austin, señala que el género no es una categoría que constate o describa una esencia prefijada en nuestro interior, sino que la misma produce y realiza el cuerpo sexuado y la identidad de género de las personas mediante actos y palabras. Cuando a una persona se le denomina "hombre" o "mujer", o se le atribuyen determinados significados "femeninos" o "masculinos", no se están constatando nuestras identidades o nuestro "sexo". Por el contrario, como indican Cabral y Benzur (2005), con dichos actos se realiza un proceso de generización sobre nosotros que vuelve la carne desorganizada en cuerpos sexuados por medio de la interpretación cultural.

Ahora bien, los aportes constructivistas no solamente encontraron cabida en las ciencias sociales, sino que también contaron con el sustento científico aportado desde la biología. Ejemplo paradigmático de ello son los estudios realizado por la bióloga norteamericana Anne Fausto-Sterling. En su texto Cuerpos sexuados: la política de género y la construcción de la sexualidad (2000), la citada autora señala que no es posible encontrar un método científico infalible para constatar el sexo de una persona, pues "nuestros cuerpos son demasiado complejos para proporcionarnos respuestas definidas sobre las diferencias sexuales. Cuanto más buscamos una base física para el sexo, más claro resulta que "sexo" no es una categoría puramente física. Las señales y funciones corporales que definimos como masculinas o

por la religión: la confesión. El autor sostiene que la idea de acudir a una persona o especialista para que en un ámbito cerrado se cuenten los relatos y experiencias sexuales deja de ser un método exclusivo de la religión para expandirse también a centros educativos y psiquiátricos. Mediante esta práctica, se logra intervenir en las personas a partir de la interpretación de los relatos que cuenta el paciente. Uno desvela sus verdades sexuales frente a un agente exterior que sabe lo que ocurre, y este interpreta nuestras sensaciones y experiencias para establecer el discurso dentro de nosotros (Fuller, 1992, pág.58). 
femeninas están ya imbricadas en nuestras concepciones del género" (pág. 19). En consecuencia, "etiquetar a alguien como varón o como mujer es una decisión social. El conocimiento científico puede asistirnos en esta decisión, pero sólo nuestra concepción del género, y no la ciencia, puede definir nuestro cuerpo. Es más, nuestra concepción del género afecta al conocimiento sobre el sexo producido por científicos en primera instancia" (pág. 17).

En concordancia con lo desarrollado por Butler, los ejemplos reales propuestos por Fausto-Sterling muestran que el marco binario sobre el sexo responde a concepciones de género prefijadas. El catalogar a personas con características cromosómicas y anatómicas ambiguas bajo un determinado sexo únicamente en base a sus genitales, prueba la existencia de una norma cultural que busca siempre afianzar un esquema binario de sexualidad que promueva la reproducción humana. En razón a ello, Fausto-Sterling (2000) también cuestiona este entendimiento del sexo, pues considera que dicha generalización ejerce un fuerte tipo de violencia frente a determinadas identidades que no encajan en dicho binarismo a pesar que "ningún varón ni mujer se ajusta al estereotipo genérico universal” (pág. 135).

Por último, la legitimidad de los cuestionamientos desde la biología al modelo médico lograron un paso trascendental en el año 2013, cuando el DMS cambió el término transexualidad por el de disforia de género. A pesar de mantener aún claras limitaciones, el lenguaje utilizado en el nuevo manual coloca mayor énfasis en el entorno como causa del malestar que sufren las personas trans, generando un lenguaje menos patologizante. El problema ya no se presenta únicamente en razón de un trastorno de la persona, sino que acarrea un diagnóstico con más variables. Asimismo, el empleo del uso género en lugar de sexo en muchas de sus explicaciones permite cuestionar la hipótesis determinista y binaria del sexo propuesta por el modelo médico.

\begin{tabular}{|c|c|c|}
\hline & \multicolumn{2}{|c|}{ Tabla 1} \\
\hline & Modelo médico & Modelo de reconocimiento \\
\hline $\begin{array}{l}\text { Concepción de } \\
\text { las identidades } \\
\text { trans }\end{array}$ & $\begin{array}{l}\text { Asume que la población trans } \\
\text { sufre algún tipo de trastorno o } \\
\text { desorden mental. }\end{array}$ & $\begin{array}{l}\text { Visión no patológica: Muestra de } \\
\text { la diversidad humana }\end{array}$ \\
\hline $\begin{array}{l}\text { Solución para } \\
\text { el problema de } \\
\text { exclusión }\end{array}$ & $\begin{array}{l}\text { La curación o normalización por } \\
\text { medio de terapias psicológicas } \\
0 \text { incluso operaciones de afir- } \\
\text { mación de género. }\end{array}$ & $\begin{array}{l}\text { Eliminación de barreras: } \\
\text { revaloración de las identidades } \\
\text { trans y transformación de los } \\
\text { discursosqueniegan sus derechos }\end{array}$ \\
\hline $\begin{array}{l}\text { Concepción } \\
\text { sobe el sexo }\end{array}$ & $\begin{array}{l}\text { Visión determinista y binaria } \\
\text { sobre el sexo }\end{array}$ & $\begin{array}{l}\text { Visión constructivista: El } \\
\text { sexo representa un concepto } \\
\text { construido socialmente }\end{array}$ \\
\hline $\begin{array}{l}\text { Manifesta- } \\
\text { ciones y } \\
\text { vigencia del } \\
\text { modelo }\end{array}$ & $\begin{array}{l}\text { 1970-1980: Reconocimiento } \\
\text { de la transexualidad en las } \\
\text { principales clasificaciones di- } \\
\text { agnósticas. El surgimiento del } \\
\text { concepto de género e identidad } \\
\text { de la década de los setenta no } \\
\text { provocó cambios. }\end{array}$ & $\begin{array}{l}\text { Década de los 80: Publicación } \\
\text { de Historia de la sexualidad de } \\
\text { Michel Foucault } \\
\text { Década de los 90: Diversificación } \\
\text { de publicaciones con visiones } \\
\text { constructivistas }\end{array}$ \\
\hline
\end{tabular}

Este fortalecimiento de la prevalencia del modelo de reconocimiento incentivó el debate sobre cuál de los parámetros debería ser utilizado para afrontar los problemas de exclusión de las personas trans. El desarrollo de esta controversia en el DIDH puede constatarse por medio de los argumentos empleados por las sentencias y documentos emitidos por tribunales y órganos internacionales. Como veremos a continuación, un análisis de dichos pronunciamientos muestra con claridad cómo los fundamentos del modelo médico fueron reemplazados progresivamente por los postulados del modelo de reconocimiento.

\section{La incorporación del modelo de reconocimiento en el DIDH}

En el año 1986, mediante el caso Rees $v$. The United Kingdom, el Tribunal Europeo de Derechos Humanos (en adelante, TEDH) emitió la primera sentencia relativa a los derechos de las personas trans en el DIDH. En esta decisión, el tribunal rechazó la demanda de Mark Rees, quien solicitaba se declare la responsabilidad internacional del Reino Unido por no modificar su nombre y sexo en su certificado de nacimiento, a pesar de haber pasado por una operación de afirmación de género. EI TEDH declaró infundada la demanda, señalando que una modificación en el certificado de nacimiento implicaría un acto de falsificación, pues el demandante no puede ser reconocido como varón para todos los efectos de la ley. Asimismo, indicó que el Estado ya había cumplido con facilitar su operación de afirmación de género, por lo que ya habría tutelado los derechos del señor Rees. Posteriormente, este criterio fue reiterado en el caso Cossey v. The United Kingdom de 1990.

Como se puede apreciar, la primera respuesta desde el DIDH frente a la realidad de las personas trans se basó en los postulados del modelo médico. Las decisiones del TEDH asumieron que un Estado cumple con sus obligaciones internacionales del Convenio Europeo de Derechos Humanos (en adelante, $\mathrm{CEDH}$ ) solamente con asegurar tratamientos médicos de afirmación de género. El pleno reconocimiento jurídico de las identidades 
trans y la transformación de los sesgos no eran tomados como parte de la solución para la situación de vulnerabilidad de esta población.

El pasó de los años comenzó a constatar la debilidad del estándar utilizado por el TEDH. La provisión de terapias de afirmación de género no era suficiente para lograr cambios sustanciales en las condiciones de precariedad que sufre la población trans. Ello generó que el DIDH cambiará de paradigma y acogiera, progresivamente, el modelo de reconocimiento para tutelar los derechos de las personas trans. Esta transformación encontró en el principio de no discriminación, por su importancia y efectos en la interpretación de las obligaciones internacionales de los Estados, una base jurídica transcendental para afianzar estándares que reviertan integralmente las condiciones de vulnerabilidad de esta población.

\subsection{El derecho a la no discriminación y los motivos prohibidos}

Uno de los principales derechos reconocidos en los tratados generales y específicos ${ }^{(2)}$ del DIDH, mediante normas amplias, normas de protección concretas y normas transversalizadas (Bregaglio, 2014), es el derecho a la igualdad y no discriminación. Si bien ambos conceptos (igualdad y no discriminación) aparecen de manera conjunta en la mayoría de normas y son difíciles de desligar, cada uno posee un contenido específico.

Mientras que el derecho a la no discriminación se centra en situaciones de diferenciación injustificada en perjuicio de una persona o grupo de personas sobre la base de un motivo prohibido; el respeto por la igualdad prohíbe las conductas que, si bien generan un trato diferenciado irrazonable, no toman en cuenta dichos motivos. Esta explicación fue planteada por Bregaglio (2014) de la siguiente forma:

“(...) la discriminación será aquel acto por el cual se diferencia arbitrariamente a una persona o grupo sobre la base de un motivo prohibido, mientras que la vulneración al derecho a la igualdad se producirá cuando exista también un trato diferenciado arbitrario (y por lo tanto una desigualdad ante la ley), pero en el cual la diferencia no tome en cuenta dichos motivos prohibidos. La vulneración de la igualdad radica, de manera similar a la discriminación, en la arbitrariedad de la diferencia (es decir, en la razonabilidad entre el motivo de la diferencia y el trato diferenciado en sí mismo), pero a distinción de la discriminación, no constituye un trato diferenciado basado en motivos prohibidos (que sí era necesario para determinar la existencia de un acto discriminatorio)" (pág. 78).

La Corte IDH también ha realizado esta diferenciación entre ambos conceptos y en el caso I.V vs. Bolivia, por primera vez, indicó las características específicas que poseen los motivos prohibidos de discriminación:

“(...) la Corte recuerda que no toda diferencia de trato será reputada discriminatoria, sino sólo aquella que se base en criterios que no puedan ser racionalmente apreciados como objetivos y razonables. Cuando el criterio diferenciador se corresponde con uno de aquellos protegidos por el artículo 1.1 de la Convención que aluden a: i) rasgos permanentes de las personas de los cuales éstas no pueden prescindir sin perder su identidad; ii) grupos tradicionalmente marginados, excluidos o subordinados, y iii) criterios irrelevantes para una distribución equitativa de bienes, derechos o cargas sociales, la Corte se encuentra ante un indicio de que el Estado ha obrado con arbitrariedad" (párr. 240).

Conforme a estos fundamentos, los órganos y tratados internacionales han establecido que será un acto de discriminación toda distinción, exclusión, restricción o preferencia, en cualquier ámbito público o privado, que se base en uno o varios de los motivos prohibidos (por ejemplo la raza, el sexo, idioma, la religión, la nacionalidad, entre otros.) y que tenga el objetivo o el efecto de anular o limitar el reconocimiento, goce o ejercicio, en condiciones de igualdad, de uno o más derechos humanos (Corte IDH, 2016a).

Esta distinción entre igualdad y no discriminación resulta importante no solo para identificar y combatir los fenómenos históricos de exclusión que han sufrido ciertos grupos de personas debido a un "paradigma de normalidad", sino que también genera, en el ámbito jurídico, efectos en la naturaleza de la obligación, y por tanto, en los criterios de valoración de la razonabilidad de la diferencia y en la intensidad de la sanción.

Sobre lo primero, la Corte IDH viene sosteniendo desde su Opinión Consultiva 16 que "en la actual etapa de la evolución del derecho internacional, el principio fundamental de igualdad y no discriminación

(2) Son tratados específicos en tanto buscan proteger a un determinado grupo de personas (niños, personas con discapacidad, mujeres) o desarrollar obligaciones concretas en relación a una particular vulneración de derechos humanos (torturas o desapariciones forzadas). 
ha ingresado en el dominio del ius cogens" (2003, párr. 101). En tal sentido, el mandato de no discriminación está revestido de carácter imperativo y genera obligaciones erga omnes "que vinculan a todos los Estados y generan efectos con respecto a terceros, inclusive particulares" (Corte IDH, 2003, párr. 101).

Respecto a la segunda cuestión, la CIDH (2001), el TEDH (2009) y la Corte IDH (2015a) han indicado que las medidas restrictivas que perjudican a personas sobre la base de un motivo prohibido se encuentran limitadas. Si bien no se prohíbe cualquier trato diferenciado de esta índole, dichas limitaciones deben basarse en necesidades imperiosas. Así, tales diferenciaciones no solamente deben pasar por un filtro de razonabilidad, sino por un escrutinio estricto de proporcionalidad. En esa línea, aplicando los pronunciamientos utilizados por tribunales nacionales e internacionales, la Corte IDH ha indicado que "la capacidad de diferenciación de las autoridades con base en esos criterios sospechosos se encuentra limitada, y solo en casos en donde las autoridades demuestren que se está en presencia de necesidades imperiosas, y que recurrir a esa diferenciación es el único método para alcanzar esa necesidad imperiosa, podría eventualmente admitirse el uso de esa categoría" (2015a, párr. 256).

Finalmente, por responder a valoraciones sociales, estos motivos no configuran una lista cerrada. Con la evolución de los contextos y utilizando los criterios previamente citados, los órganos internacionales han incorporado nuevas categorías prohibidas. De acuerdo con el Comité de Derechos Económicos, Sociales y Culturales, el análisis para la incorporación de nuevos motivos prohibidos debe ser lo más flexible posible e incluir otras formas de trato diferencial que no puedan justificarse de forma razonable u objetiva (1994). Este es el caso de la identidad de género, que no se encuentra textualmente reconocida en ningún tratado general de derechos humanos que se encuentre en vigor, pero que, como veremos a continuación, ha sido configurada como motivo prohibido de discriminación en virtud de la jurisprudencia internacional.

\subsection{Los primeros pronunciamientos: la pionera (pero limitada) jurisprudencia del TEDH}

Tras los pronunciamientos en los casos Rees y Cossey, el TEDH declaró por primera vez la responsabilidad internacional de un Estado por no rectificar los documentos de identidad de una persona trans que pasó por un procedimiento de afirmación de género en el caso $B$. v. France de 1992. En dicha sentencia, el tribunal indicó que se produce una violación del derecho a la privacidad, cuando se expone a una persona trans a revelar información privada sin su consentimiento, debido a la incongruencia entre su apariencia física y sus documentos de identidad.
No obstante, para sustentar su posición, el Tribunal no cuestionó los fundamentos expuestos en las sentencias emitidas con anterioridad, indicando únicamente que dicho caso era distinto a las situaciones que había conocido en el pasado en razón de los marcos jurídicos internos de Francia y Reino Unido. De este modo, su argumentación se sustentó en que la legislación del Estado francés proveía más facilidades para cambiar los datos establecidos en los certificados de nacimiento, a diferencia del ordenamiento jurídico inglés donde los registros buscaban dar fe de un hecho histórico como la asignación de sexo al momento del nacimiento.

La endeble argumentación empleada por el TEDH en dicha sentencia no permitió avances significativos en miras al reconocimiento de la identidad de género a nivel internacional. Si bien se mostraba un mayor grado de sensibilidad respecto a las barreras que sufren las personas trans, la falta de consenso de la comunidad europea y el estado de los estudios referidos a las personas trans en la época no permitieron una respuesta jurídica consistente. Prueba de ello es que en el caso Sheffield and Horsham v. The United Kingdom de 1998, el Tribunal utilizó los mismos argumentos empleados en sus primeras sentencias, referidos a la incertidumbre sobre la situación médica de las personas trans.

No fue hasta la sentencia del caso Christine Goodwin vs. The United Kingdom del 2002 que el TEDH determinó que un Estado parte del CEDH incumple sus obligaciones internacionales cuando no permite la rectificación de nombre y sexo de las personas trans luego de haberse sometido a una cirugía de afirmación de género. En el referido caso, Christine Goodwin demandó al Reino Unido por la violación de los derechos contemplados en los artículos 8 (derecho al respeto a la vida privada y familiar), 12 (derecho a contraer matrimonio), 13 (derecho a un recurso efectivo) y 14 (prohibición de discriminación) del CEDH.

Apartándose de su jurisprudencia y tras analizar la situación concreta de la señora Goodwin, el tribunal declaró que el Reino Unido había violado los artículos 8 y 12 del CEDH. Respecto del primer artículo, el TEDH señaló que la situación ambivalente 
que viven las personas trans que han pasado por operaciones quirúrgicas, por la falta de coherencia entre lo que señala su cuerpo y lo que establecen sus documentos personales, es una afectación al derecho a la vida privada. Además, la Corte enfatizó que resultaba incoherente que el Estado no otorgará el debido reconocimiento jurídico a las personas trans cuando las mismas habían pasado por un proceso médico financiado o avalado por los propios servicios de salud del Estado:

“(...) La coherencia de las prácticas administrativas y legales dentro de los sistemas nacionales debe considerarse un factor importante en la evaluación realizada en base al artículo 8 del Convenio. Cuando un Estado ha autorizado el tratamiento y cirugía para aliviar las condiciones de una persona transexual, financiando o apoyando en el financiamiento (...). parece ilógico negarse a reconocer las consecuencias legales del resultado que acarean tales tratamientos" ${ }^{\prime(3)}$ [énfasis agregado] (párr. 81-83).

En referencia a los discursos médicos sobre las personas trans, el TEDH indicó que no existían conclusiones definitivas sobre las causas que llevan al "transexualismo". No obstante, a juicio del tribunal, dadas las numerosas y dolorosas intervenciones que se requieren para realizar el procedimiento de afirmación de género, no era lógico señalar que dicha decisión sea un mero capricho y, por ende, cualquier debate científico existente sobre el tema resultaba irrelevante. De la misma manera, consideró que los argumentos referidos a la imposibilidad de modificar el patrimonio cromosómico tampoco constituían una barrera al reconocimiento, dados los diversos componentes que conforman el sexo. En consecuencia, concluyó que los avances médicos y científicos de dicha época no proveían información determinante para rechazar el reconocimiento legal de las personas trans que han pasado por procesos quirúrgicos.

Finalmente, el TEDH precisó que el reconocimiento por parte del Estado de esta nueva identidad no generaba afectaciones al interés público ni interfería con la función registral, el derecho de familia, las sucesiones, entre otros. En palabras del tribunal:

“(...) Toda "dificultad aparente”, particularmente en el área del Derecho de Familia, es manejable y aceptable si se circunscribe al caso de las personas transexuales que han pasado por una operación y se encuentran plenamente desarrolladas. (...) No se ha demostrado ninguna dificultad concreta o sustancial, o detrimento al interés público, que pueda derivarse del cambio de estatus de las personas transexuales y, respecto a otras posibles consecuencias, la Corte considera que puede esperarse razonable que la sociedad tolere ciertos inconvenientes para que los individuos puedan vivir dignamente y de conformidad con la identidad sexual elegidas por ellos a un gran costo personal"(4) (pág. 91).
Los argumentos de esta jurisprudencia fueron reiterados en las sentencias $I$. $v$. United Kindgom (publicada el mismo día que el caso de Goodwin), y posteriormente en Grant v. The United Kindgom del año 2006, sin realizar cambios significativos. Ahora bien, como se puede apreciar, a pesar de este primer gran avance, las sentencias no reconocieron que hubiese existido un trato discriminatorio, pues no se entendía a la identidad de género como parte de los motivos prohibidos de discriminación. Asimismo, los criterios utilizados por la Corte se basaron mayoritariamente en el hecho de que Christine Goodwin ya había pasado por una operación quirúrgica de afirmación de género, manteniendo una visión todavía cercana con el modelo médico.

\subsection{Cuando el "soft law" se vuelve norma:} el impacto de los Principios de Yogyakarta El segundo hito importante para lograr la tutela de la identidad de género como motivo prohibido de discriminación en el DIDH fue la publicación de los Principios de Yogyakarta. Estos principios fueron elaborados por un panel de especialistas en legislación internacional en el año 2007 y desarrollan ampliamente la manera en la que los Estados deben tutelar los derechos de las personas LGTBI. En noviembre de 2017, dicho instrumento fue revisado y actualizado (Principios de Yogyakarta Plus 10), aclarando los deberes que tienen los Estados en esta materia.

Uno de los principales aportes de este instrumento es el establecimiento de una definición de identidad género. Se definió como una característica personalísima que representa "la vivencia interna e individual del género tal como cada persona la siente profundamente, la cual podría corresponder o no con el sexo asignado al momento del nacimiento" (párr. 6). Es decir que, mientras la identidad de género de las personas cisgénero se corresponde con las expectativas social y culturalmente construidas que se le asignaron al momento de nacer, en las personas trans no hay coincidencia entre la identidad de

(3) Traducción propia

(4) Traducción propia 
género que construyen y el sexo que se les impuso al nacer. Asimismo, el Principio 2 establece que todas las personas gozan de todos los derechos humanos, sin discriminación por motivos de orientación sexual e identidad de género. De tal forma, este instrumento internacional se constituye como el primero que reconoce la identidad de género como un motivo prohibido de discriminación.

A pesar de que estos Principios no son, per se, de obligatorio cumplimiento para los sujetos de derecho internacional (son fuente auxiliar del Derecho Internacional), los mismos tuvieron un impacto significativo en los pronunciamientos posteriores de los órganos de protección de derechos humanos, permitiendo que se reconozca la identidad de género como motivo prohibido de discriminación. Así, el primero en dar este paso fue el Comité de DESC en el año 2009:

"En "cualquier otra condición social", tal y como se recoge en el artículo 2.2 del Pacto, se incluye la orientación sexual. Los Estados partes deben cerciorarse de que las preferencias sexuales de una persona no constituyan un obstáculo para hacer realidad los derechos que reconoce el Pacto, por ejemplo, a los efectos de acceder a la pensión de viudedad. La identidad de género también se reconoce como motivo prohibido de discriminación" (párr. 32).

Esta postura fue reiterada en diversos pronunciamientos del propio Comité (2016a y 2016 b) y replicada en el resto de ellos. De esta manera, el Comité de Derechos Humanos (2014a), el Comité para la Eliminación de Todas las Formas de Discriminación Contra la Mujer (2010a y 2010b), el Comité de los Derechos del Niño (2013) y el Comité Contra la Tortura (2012) también han reconocido la identidad de género como parte de los motivos prohibidos de discriminación.

\subsection{Apertura al modelo de reconocimiento: inclusión jurisprudencial de la identidad de género como motivo prohibido de discriminación}

La incorporación del modelo de reconocimiento al DIDH logró un paso trascendental con la aceptación de la identidad de género como motivo prohibido por tribunales internacionales. Dado que estos órganos son los principales encargados de dirimir las controversias jurídicas del DIDH mediante la interpretación de los tratados que se encuentran bajo su competencia, sus pronunciamientos son vinculantes para los Estados parte de dichos instrumentos.

En el ámbito del Sistema Interamericano de Derechos Humanos (en adelante, SIDH), la primera decisión sobre el tema se dio en el caso Atala Riffo y niñas vs. Chile del año 2012. Los hechos de la sentencia se remontan a 1994 cuando, luego de finalizar su matrimonio, Karen Atala Riffo estableció de mutuo acuerdo con el padre de sus tres hijas que las niñas quedarían bajo su custodia. Sin embargo, años después la Corte Suprema de Chile le otorgó la custodia al padre, al considerar que la convivencia de la señora Atala con su pareja del mismo sexo atentaba contra el interés superior de las niñas.

La Corte IDH declaró que se había configurado una violación de los derechos de Karen Atala, producto del trato discriminatorio que recibió por parte de los tribunales nacionales chilenos. Para sustentar su posición, la Corte señaló lo siguiente:

"Teniendo en cuenta las obligaciones generales de respeto y garantía establecidas en el artículo 1.1 de la Convención Americana, los criterios de interpretación fijados en el artículo 29 de dicha Convención, lo estipulado en la Convención de Viena sobre el Derecho de los Tratados, las Resoluciones de la Asamblea General de la OEA, los estándares establecidos por el Tribunal Europeo y los organismos de Naciones Unidas (...), la Corte Interamericana deja establecido que la orientación sexual y la identidad de género de las personas son categorías protegidas por la Convención (...). En consecuencia, ninguna norma, decisión o práctica de derecho interno (...) pueden disminuir o restringir, de modo alguno, los derechos de una persona a partir de su orientación sexual" (o identidad de género) (párr. 91).

Como se puede apreciar, a pesar que el caso versaba sobre una situación de discriminación por motivos de orientación sexual, la Corte IDH aprovechó la oportunidad para precisar que la identidad de género también forma parte de los motivos prohibidos de discriminación del DIDH. Ello debido a que ambas categorías poseen ciertas similitudes, en tanto responden a características personales que han sido históricamente reprimidas por normas culturales de índole sexual. Dicha situación será un constante en la jurisprudencia de la Corte IDH, pues hasta el momento no hay una sentencia en un caso contencioso que se refiera a la protección de los derechos de las personas trans ${ }^{(5)}$.

La jurisprudencia enunciada en el caso de Karen Atala fue reiterada en la sentencia del caso Duque vs. Colombia. En dicho pronunciamiento, la Corte IDH declaró la responsabilidad internacional del Estado de Colombia por discriminar al señor Ángel Alberto Duque por motivos de orientación sexual mediante la normativa nacional en materia de seguridad social. Además, en 
dicha sentencia se utilizó por primera vez los Principios de Yogyakarta para reconocer la identidad de género como un motivo prohibido de discriminación, y aclarar las obligaciones internacionales que tienen los Estados sobre la materia (2016b).

Finalmente, en lo que respecta al Sistema Europeo también ha habido cambios importantes en los últimos años. En el año 2010, el TEDH varió su línea argumentativa y señaló en la sentencia del caso P.V. vs. España que el artículo $14 \mathrm{del}$ Convenio contempla como parte de los motivos prohibidos a la "distrofia de género". Si bien la terminología empleada no es la más adecuada, la misma fue aclarada en el año 2015 en la sentencia del caso Identoba and others v. Georgia donde se reconoce explícitamente que la identidad de género merece ser protegida al formar parte de los criterios prohibidos de discriminación del DIDH.

\section{El estándar de protección actual del derecho a la identidad de las personas trans}

En el 2017 la Corte IDH emitió su Opinión Consultiva 24, en la que establece cómo los Estados deben proteger el derecho a la identidad de las personas trans mediante sus sistemas de identificación. En la Tabla 2 resumimos las principales características que deben cumplir los procedimientos de reconocimiento de género de conformidad con la citada opinión.

\begin{tabular}{|l|}
\hline \multicolumn{1}{|c|}{ Tabla 2} \\
\hline $\begin{array}{l}\text { Deben permitir la adecuación integral de la identidad de género: nombre, imagen } \\
\text { fotográfica, género o sexo, entre otros. }\end{array}$ \\
\hline $\begin{array}{l}\text { Solamente debe basarse en el consentimiento libre e informado del solicitante. } \\
\text { No se pueden exigir intervenciones médicas, certificados psiquiátricos u otros } \\
\text { documentos desvirtúen la naturaleza declarativa del procedimiento. }\end{array}$ \\
\hline $\begin{array}{l}\text { Los procedimientos y modificaciones deben ser confidenciales y los documentos no } \\
\text { deben reflejar los cambios realizados. }\end{array}$ \\
\hline Los procedimientos deben ser expeditos y tender a la gratuidad. \\
\hline No deben excluir de forma absoluta a Ixs niños, niñas y adolescentes \\
\hline El procedimiento debe ser materialmente administrativo. \\
\hline
\end{tabular}

Asimismo, la Corte IDH señala que los Estados poseen una potestad sumamente limitada al momento de establecer los requisitos que deben cumplir las personas trans para lograr el reconocimiento de sus datos identitarios, pues "de acuerdo con los principios de igualdad y no discriminación (...), no resulta razonable establecer un trato diferenciado entre las personas cisgénero y transgénero que pretenden llevar a cabo correcciones en los registros y los documentos de identidad" (2017, párr. 131). De este modo, la OC-24/17 constata la consolidación del modelo de reconocimiento dentro del DIDH, al utilizar como sustento de su argumentación el principio de no discriminación por motivos de identidad de género.

A pesar de ello, muchos de los puntos abordados en la OC-24 siguen generando debates a nivel interno. En algunos casos, ello se debe a la existencia de pronunciamientos contradictorios en el ámbito internacional. Por esta razón, para finalizar el presente artículo nos concentraremos en analizar los puntos de la OC-24/17 que pueden suscitar más controversias. En este análisis, tomaremos en cuenta, cuando corresponda, los pronunciamientos que han emitido otros órganos a nivel internacional sobre el punto específico, y argumentaremos cuál es el estándar que debe primar en el DIDH.

\subsection{Prohibición de exigir operaciones de afirmación de género ylo terapias hormonales \\ Este punto ha sido materia de diversos} pronunciamientos a nivel internacional. En el ámbito de la ONU, el Comité de Derechos Humanos (2017b, 2016 y 2013), el Comité CEDAW (2010, 2014b, 2015 y 2017), el Comité DESC (2014) y el Comité de los Derechos del Niño (2016a) han señalado su preocupación por la existencia de leyes que obligan a las personas trans a pasar por operaciones de afirmación de género o terapias hormonales de manera previa a su reconocimiento en los documentos y registros identitarios. En ámbitos regionales, el TEDH (2017) y la CIDH (2017) han indicado que la referida exigencia resulta una intromisión desproporcional en los derechos de las personas trans.

A pesar de ello, se suelen mantener tres argumentos que defienden la legitimidad de este requisito. En primer lugar, se alega que el sexo es un elemento netamente genital y binario del ser humano, por lo que cualquier cambio en los sistemas de identificación debe requerir el sometimiento del beneficiario a una operación de afirmación de género.

(5) No obstante, no falta mucho para que esta situación cambie. El 30 de abril de 2019 la CIDH presentó a la Corte IDH el caso de Vicky Hernández y familia vs. Honduras. En el caso se denuncia que el Estado ejecutó a la Sra. Vicky Hernández por su condición de activista y mujer trans y no investigó con debida diligencia lo ocurrido. 
Como segundo cuestionamiento, se señala que resulta razonable exigir intervenciones médicas, ya que todas las personas trans necesariamente requieren dichos tratamientos para adaptar su cuerpo a su identidad de género. Finalmente, se suele argüir que este requerimiento es imprescindible para garantizar los principios de seguridad jurídica y orden público, debido a los posibles riesgos que podrían generar cambios tan sencillos en los documentos identitarios en los sistemas de identificación administrados por los Estados. Examinaremos cada punto por separado para explicar argumentativamente por qué los pronunciamientos a nivel internacional aciertan en este tema.

En relación al primer punto, como indicamos previamente, el modelo de reconocimiento postula que el sexo es un concepto construido socialmente que agrupa determinadas funciones y características conforme a un paradigma cultural. En ese sentido, es posible interpretar y entender dicha categoría más allá del criterio netamente genital. Al tener dos posibles concepciones sobre qué es el sexo, surge la controversia sobre cuál de las mismas debe ser acogida a nivel jurídico. Al respecto, consideramos que los pronunciamientos internacionales muestran correctamente que una adecuada aplicación de los principios de interpretación del DIDH constatan que debe superarse la visión binaria y determinista del sexo, a fin de acoger lo postulado por el modelo de reconocimiento.

Conforme a lo señalado por la Corte IDH (2012c y 2016c), las obligaciones internacionales de derechos humanos deben interpretarse de manera dinámica o evolutiva. Ello implica entender que los tratados sobre esta materia son instrumentos vivos que requieren ser interpretados conforme a la evolución de los tiempos y las condiciones de vida actuales. Además, en caso exista una disputa entre el resultado de dos posibles interpretaciones, el mismo tribunal ha señalado que debe aplicarse el principio pro persona en la resolución de controversias, a fin de aplicar siempre la interpretación más favorable al ser humano y cumplir con el objeto y fin de los tratados de derechos humanos. Por ello, teniendo en cuenta que los avances contemporáneos del conocimiento muestran una concepción del sexo más amplia y que optimiza mejor los derechos de las personas trans, resulta imperativo a nivel jurídico acoger la concepción postulada por el modelo de reconocimiento.

En segundo lugar, el argumento de que toda persona trans requiere intervenir su cuerpo cae en un estereotipo de género que carece de legitimidad. La afirmación se basa en una presuposición que excluye a las identidades trans que no necesitan pasar por una operación de afirmación de género para expresar una identidad de género diversa. Si bien existen quienes eligen acudir a cirugías de afirmación de género o terapias hormonales, la realidad nos muestra que no todas las personas trans precisan de dichas intervenciones. En consecuencia, el argumento cae en un estereotipo sobre cómo las personas trans desarrollan su identidad, en base a determinados patrones culturales sobre la masculinidad y la feminidad.

Al tratarse de un estereotipo, el mismo no representa un argumento válido que cumpla con la razonabilidad exigida por el DIDH para avalar situaciones de tratos diferenciados por motivos de identidad de género. Si bien hasta el momento solo la Corte IDH (2014 y $2015 b)$ ha tenido la oportunidad de referirse a estereotipos de género en perjuicio de mujeres en investigaciones judiciales y sobre concepciones estereotipadas respecto a la idoneidad para ejercer la maternidad o paternidad en el cuidado de niños o niñas (2012a y 2012b), consideramos perfectamente aplicable la lógica argumentativa a la situación de las personas trans.

Finalmente, el tercer argumento, referido a que el citado requisito optimiza los principios de seguridad jurídica y orden público, no supera el juicio estricto de proporcionalidad que debe aplicarse a los tratos diferenciados basados en la identidad de género de las personas. Respecto a la finalidad de la restricción, consideramos que la medida efectivamente tutela objetivos legítimos como los principios de seguridad y orden público, al tener como propósito el establecimiento de un sistema de identificación que permita lograr el cumplimiento de las obligaciones jurídicas contraídas por las personas. Asimismo, el requisito cumple también con el criterio de idoneidad, al ser adecuado para conseguir la finalidad explicada previamente. Al condicionar la rectificación de datos identitarios a pasar por un procedimiento de afirmación de género se optimiza la seguridad jurídica, pues se genera certeza que solo las personas trans puedan beneficiarse de dicho procedimiento. Ello, a su vez, permite una maximización del orden público al lograr que las personas no abusen de este tipo de mecanismos para eludir a la justicia, consolidando un sistema de identificación sin fallas.

Ahora bien, a pesar de ser adecuada para conseguir un fin legítimo, la medida resulta manifiestamente contraria al estándar planteado por el criterio de necesidad, en tanto es posible conseguir el mismo grado de optimización del orden público y la seguridad jurídica mediante medidas menos lesivas. 
Antes de afectar la integridad física de las personas trans, el sistema debería tener garantías institucionales para evitar que los cambios en documentos identitarios no generen el incumplimiento de obligaciones jurídicas por las personas que lo solicitan. Ello puede conseguirse mediante un sistema de comunicación entre los aparatos estatales que tienen el deber de garantizar que toda persona cumpla con las normas jurídicas (por ejemplo, el Ministerio Público y el Poder Judicial). Bastaría que dichos órganos mantengan un sistema de coordinación entre sí para lograr que cualquier cambio en los datos de identificación de las personas sea conocido por el Estado, a fin de prevenir cualquier obstaculización del sistema de justicia.

Sin perjuicio de lo anterior, la referida medida tampoco cumple con la proporcionalidad en sentido estricto. Además de restringir al derecho a la identidad, el requisito genera severas limitaciones en otros derechos humanos de las personas trans sin guardar un adecuado balance con los principios maximizados. En primer lugar, se produce una vulneración al derecho a la integridad personal, pues condiciona el ámbito de libertad que tienen las personas sobre sus propios cuerpos. Diversas fuentes a nivel internacional han establecido que toda intervención o acto médico debe contar con el consentimiento libre de las personas afectadas, salvo circunstancias de urgencia. Dadas las situaciones de estrés que viven las personas trans, debido a la falta de reconocimiento legal de su identidad de género, la decisión de pasar por las intervenciones médicas requeridas legislativamente no es tomada de forma verdaderamente libre. Por el contrario, la misma puede representar una salida desesperada en aras de lograr cierto grado de aceptación social que corre el riesgo de generar sentimientos negativos en perjuicio de la persona afectada. Por ello, cuando se condiciona la rectificación de datos identitarios al sometimiento de intervenciones médicas, que incluso pueden ser irreversibles, se configura una situación coercitiva en perjuicio de su derecho a la integridad física.

Además, algunos tipos de intervenciones también pueden configurarse como afectaciones a los derechos sexuales y reproductivos, la vida privada y la familiar. Como ha sido desarrollado por el TEDH (2013) y la Corte IDH (2016a), existe una fuerte interdependencia entre los citados derechos, dado que buscan que toda persona pueda efectivizar ciertos planes de vida respecto a su vida sexual, cuántos hijos/as una persona quiere tener y bajo qué parámetros desea fundar una familiar. Cuando las personas pasan por intervenciones médicas producto de presiones externas y que implican la pérdida de capacidades reproductivas se puede configurar una situación de esterilización no voluntaria que afecta los citados derechos.

Por los argumentos desarrollados, queda en evidencia que el requisito de pasar por este tipo de procedimientos médicos cae en estereotipos de género y no cumple con los estándares del DIDH para la limitación de derechos. En consecuencia, el requisito no puede ser empleado por los Estados en sus legislaciones, al vulnerar los derechos de las personas trans.

\subsection{Prohibición de exigir la presentación de un certificado médico que acredite la identidad de género trans}

Este punto ha causado mayor polémica a nivel internacional. Si bien además de la OC 24/17, el ACNUDH (2016a y 2017b) y la CIDH (2017) han señalado que las leyes de identidad de género no deben exigir el sometimiento a evaluaciones psiquiátricas o diagnósticos médicos, el TEDH (2017) ha llegado a una conclusión diferente. En aplicación del margen de apreciación nacional, el tribunal señaló que el referido condicionamiento no vulnera los derechos de las personas trans $y$, en consecuencia, los Estados tienen libertad de colocarlo dentro de su legislación. Asimismo, a nivel de Comités de la ONU, solo el Comité CEDAW (2014a) ha señalado con claridad su oposición al requisito de pasar por una evaluación psiquiátrica. Con menos precisión, el Comité DESC (2011) ha indicado su preocupación por colocar requisitos que cataloguen a las personas trans como "enfermos mentales".

A pesar de esta divergencia, consideramos que condicionar el reconocimiento identitario de las personas trans al sometimiento de este requisito tampoco cumple con los criterios del DIDH para la limitación de derechos. La asociación de las identidades trans con criterios psiquiátricos responde a un modelo médico que históricamente ha fomentado la patologización de las personas trans, reforzando los estereotipos que mantienen a esta población en una situación de vulnerabilidad. En lugar de asumir que las identidades son diversas, se emplea una lógica cisnormativa que entiende que las personas trans constituyen una excepción que debe ser corroborada y analizada por la medicina.

Por ello, el ACNUDH, la CIDH y la Corte $\mathrm{IDH}$, en los pronunciamientos citados, advierten que el paradigma que sustenta este requisito genera un fuerte efecto negativo en el goce y ejercicio de los derechos de las personas trans que debe ser tomado en consideración al momento de evaluar la razonabilidad de la medida. En concreto, la OC 24/217 indica que los certificados médicos, psicológicos o psiquiátricos “además de tener 
un carácter invasivo (...), descansan en el supuesto según el cual tener una identidad contraria al sexo que fue asignado al nacer constituye una patología. Es así como ese tipo de requisitos o certificados médicos contribuyen a perpetuar los prejuicios asociados con la construcción binaria de géneros masculino y femenino" (párr. 130).

En consecuencia, y en base al análisis realizado en el acápite anterior, si bien esta exigencia también es adecuada para tutelar la seguridad jurídica y el orden público, consideramos que en este caso tampoco se cumplen los parámetros del juicio estricto de proporcionalidad. La implementación de las garantías institucionales indicadas previamente representa una medida menos lesiva e igualmente efectiva para la materialización de los principios citados.

Por su parte, tampoco se cumple con el requisito de proporcionalidad en sentido estricto, en tanto existe una seria afectación en el derecho a la identidad y vida de la población trans que no guarda un adecuado balance con los fines que se buscan tutelar. En muchas ocasiones las entrevistas con personal psiquiátrico o psicológico acarrean largas de sesiones de preguntas y cuestionamientos, donde la persona se ve expuesta a revelar aspectos íntimos de su vida sin que exista un legítimo interés en compartir dicha situación con otra persona, corriendo el riesgo de generar sensaciones de humillación en aras de lograr un adecuado reconocimiento. Además, tal situación perpetua los estereotipos médicos en perjuicio de dichas personas. Debido a ello, el requisito de contar con un certificado médico tampoco representa un límite válido.

\subsection{Prohibición de requerir la disolución del matrimonio o la unión civil}

La OC-24/17 no realiza consideraciones propias sobre este punto. No obstante, dicha decisión mencionó que el ACNUDH (2016a) ha señalado que los Estados deben abstenerse de colocar como requisito en su legislación que las personas trans no posean un vínculo matrimonial o conyugal previo a la rectificación de su identidad de género en sus documentos de identificación. Además, el mismo criterio ha sido utilizado por el Comité de Derechos Humanos (2014b y 2017a). En su pronunciamiento más reciente, el Comité enfatizó que obligar a las personas trans a disolver sus vínculos matrimoniales vigentes al momento de solicitar la rectificación de datos identitarios implica un acto discriminatorio basado en el estado civil que incumple con su obligación de asegurar que todas las personas sean iguales ante la ley.

Sin embargo, nuevamente esta línea argumentativa no ha sido totalmente acogida por el TEDH. En el caso Hämäläinen vs. Finlandia (2014), el Tribunal resolvió que condicionar la rectificación de los documentos de identificación de una persona trans a la conversión de su vínculo matrimonial en una unión civil no viola sus derechos humanos, toda vez que el margen de apreciación nacional no obliga a los Estados a reconocer el matrimonio entre personas del mismo sexo. Asimismo, indicó que la regulación de las uniones civiles en Finlandia no poseía diferencias sustanciales respecto a la figura del matrimonio, por lo que el requisito no generaba una clara afectación de derechos.

En contraposición con lo decidido por el TEDH, el parámetro planteado en los primeros pronunciamientos resulta más acorde a los principios del DIDH. La exigencia de no contar con vínculos matrimoniales o de modificarlos al momento de solicitar la rectificación no persigue una finalidad legítima para limitar derechos, pues la presencia de cierto estado civil no representa un riesgo a la seguridad jurídica o el interés público. El resguardo del modelo tradicional de familia bajo un estándar hetero-normativo no constituye una finalidad legítima para restringir derechos humanos, al no asentarse en una necesidad imperiosa. Al respecto, la Corte IDH ha indicado con claridad que la protección que otorga CADH a las parejas del mismo género trasciende el ámbito meramente patrimonial e incluye su reconocimiento mediante la garantía del matrimonio (2017). En consecuencia, lejos de representar una medida que resguarda el orden público, la restricción de derechos en base a la orientación sexual de las personas debe ser superada y no puede ser utilizada para limitar más derechos.

\subsection{La situación de lxs niñxs y adolescentes} El Comité de los Derechos del Niño recomendó al Estado de Chile en sus observaciones finales que adopte medidas legislativas para reconocer la identidad de género de Ixs niñxs trans (2015). En el mismo sentido, a la par de la OC-24/17, la CIDH (2017) y el ACNUDH (2016b) han indicado que la tutela brindada por leyes de identidad de género debe extenderse a Ixs niñxs y adolescentes (en adelante, NNA).

Los referidos pronunciamientos pueden generar desconcierto frente al clásico régimen de capacidad jurídica restrictiva hacia Ixs NNA. Mediante una interpretación primordialmente paternalista del principio de interés superior del niño, la mayoría de legislaciones han establecido un parámetro prácticamente infranqueable bajo el cual 
solo las personas de dieciocho años o más pueden ejercer plenamente sus derechos. En el caso de Ixs NNA trans, este estándar solo permitiría que se produzca una rectificación en sus documentos de identificación con el consentimiento de sus progenitores o personas tutoras.

Esta situación no resulta válida a luz de los estándares actuales del DIDH. La entrada en vigor de la Convención de los Derechos del Niño inauguró un nuevo modelo que reconoce a lxs NNA como sujetos de derechos y no meramente como objetos de protección. En ese sentido, la tutela cambió de una visión de autoridad a una perspectiva de libertad para el ejercicio de los derechos. Prueba de ello, por ejemplo, es el reconocimiento que todx NNA tiene derecho a ser oído en los procesos o procedimientos que puedan afectar sus intereses (Art. 12 de la Convención de los Derechos del Niño). Como bien ha señalado el Comité de los Derechos del Niño (2009), ello acarrea la obligación de los Estados de asegurar que todo proceso o procedimiento sea transparente, informativo, voluntario, respetuoso, pertinente, inclusivo y adaptado para Ixs NNA.

No obstante, el estándar plantea retos más grandes. La muestra más clara del giro interpretativo inaugurado con la Convención de los Derechos Niño está graficada en el principio de autonomía progresiva de Ixs NNA, establecido en el art. 5 del referido tratado. Se entiende que Ixs NNA no adquieren la madurez necesaria para regirse autónomamente únicamente cumplidos los dieciocho años, sino que su capacidad para tomar decisiones sobre su vida se va perfeccionando con el paso del tiempo. En tanto se muestre mayor autonomía, el Derecho debe incrementar el ámbito de decisión de Ixs NNA en los aspectos esenciales de sus vidas.

Aplicando ello al caso de Ixs NNA, si son las personas tutoras quienes solicitan la rectificación de los datos identitarios, las autoridades responsables deben habilitar mecanismos que permitan escuchar al NNA. De no contar con la autorización de las tutoras, la legislación no puede colocar una barrera absoluta que afecte el derecho a la identidad de las personas beneficiarias. La corroboración de las condiciones citadas debe ser realizada mediante una entrevista dentro del procedimiento que cumpla con los estándares planteados por la Convención de los Derechos Niño y no mediante un proceso judicial engorroso. De conformidad con el principio de autonomía progresiva, si lxs NNA que solicitan la rectificación poseen un adecuado nivel de madurez y muestran que no se encuentran representados con los datos identitarios asignados al momento de sus nacimientos, se debería reconocer su identidad de género.

\subsection{Punto pendiente: no mantener un sistema binario de identificación}

A la fecha, los pronunciamientos a nivel internacional han optado por no cuestionar la necesidad de establecer un sistema de identificación en base al género de las personas.
Sin embargo, esta propuesta solamente será una vía adecuada para tutelar los derechos de las personas trans si no excluye a las identidades no binarias. Como explicamos previamente, distintos discursos de poder han buscado encajar la identidad de las personas en un simple binomio masculino $y$ femenino, en aras de generar condiciones que favorezcan la reproducción humana. No obstante, la realidad nos muestra que existen identidades de género diversas que superan dicha limitación. Al ser el resultado de un proceso cultural, nada impide que existan personas que desarrollen una identidad fuera del paradigma reproductivo. Por ello, los sistemas de identificación deben incorporar alternativas para que las personas se puedan representar fuera del binomio masculino o femenino. De lo contrario, la medida estaría discriminando a un sector dentro de la comunidad trans, generando que la medida de solución solo perpetúe nuevas situaciones de falta de reconocimiento y exclusión.

Por ello, resulta sumamente grave que la OC-24/17 no se haya pronunciado sobre este punto, toda vez que dicha omisión puede generar una falta de reconocimiento y protección de las personas de género no binario. Si bien, a nivel de derecho internacional, aún no existe una decisión general y definitiva sobre este asunto, es posible encontrar algunos pronunciamientos concretos que indican cómo los Estados deben respetar el derecho a la identidad de las personas de género no binario. Por ejemplo, en sus observaciones finales al Estado de Nepal, el Comité de los Derechos del Niño felicitó que los sistemas de identificación hayan añadido una tercera categoría de género, distinta de hombre y mujer (2016b). Asimismo, el ACNUDH ha señalado que las leyes de identidad de género deben ser inclusivas de las identidades de género no binarias a fin de garantizar en igualdad de condiciones los derechos de la población trans (2016a y 2016b).

\section{Reflexión y conclusión: hacia un modelo de autoidentificación y despatologización}

La Ley de identidad de género- Ley 26743

promulgada por Argentina en el año 2012 
resultó sumamente vanguardista en materia de derechos humanos, al no colocar requisitos estrictos e invasivos para que las personas trans puedan rectificar sus datos identitarios. A primera impresión, los estándares empleados en dicha legislación parecieran configurarse como una máxima de protección, difícilmente exigible a otros Estados.

No obstante, los efectos del principio de no discriminación por identidad de género en la interpretación del derecho a la identidad deriva en conclusiones distintas. Lejos de constituirse como un tope, el modelo de autoidentificación y despatologización representa el piso mínimo que deben garantizar las autoridades estatales en base al DIDH. Es decir, un sistema donde el requisito esencial para el reconocimiento sea la declaración jurada de la beneficiaria y no la evaluación de terceras personas o la forma en la que el peticionario manifieste su identidad de género.

Tal reflexión está sustentada en los resultados de la presente investigación. A continuación presentamos un resumen de las principales conclusiones:

- El entendimiento de las identidades trans ha pasado por dos modelos de comprensión: un modelo médico y un modelo de reconocimiento. El primer modelo utiliza una concepción de sexo estática, binaria y esencialista para concluir que las personas trans poseen una enfermedad que debe ser curada. En razón a ello, la medicalización de esta población se propone como la solución para superar su situación de exclusión. En contraste con este paradigma, el segundo modelo utiliza una concepción constructivista que rompe el esquema binario del sexo. Se entiende que las identidades trans son una expresión de la diversidad humana que han sufrido las consecuencias de un discurso que busca limitar todas aquellas expresiones que no promueven la reproducción humana. Por ello, la respuesta hacia el contexto de opresión que padecen las personas trans se orienta a la eliminación de las barreras que impiden su libre desarrollo en sociedad, mediante la revaloración de sus identidades y la transformación de los discursos que niegan sus derechos.

- Actualmente eIDIDH ha acogido el modelo de reconocimiento para tutelar los derechos de la población trans. La inclusión de la identidad de género como motivo prohibido de discriminación, tras un largo proceso de especificación jurisprudencial, ha generado que los Estados tengan el deber de adoptar medidas positivas para tutelar los derechos de la población trans. Asimismo, bajo el mismo estándar, todo trato diferenciado o desigual en perjuicio de las personas trans debe superar un escrutinio estricto y basarse en razones imperiosas para ser válido.

- En base al principio de no discriminación por razones de identidad de género, los Estados tienen la obligación de implementar un procedimiento específico para la rectificación de los datos identitarios de la población trans. Tal mecanismo debe priorizar la declaración jurada de la beneficiaria, sin someter el reconocimiento a la evaluación de terceras personas o a la manera en que el peticionario manifiesta su identidad de género. Dicha medida debe tomar en consideración la situación de las personas trans de género no binario.

\section{Referencias bibliográficas}

Bregaglio, Renata (2014). Alcances del mandato de no discriminación en la Convención sobre los Derechos de las Personas con Discapacidad. En Salmón y Bregaglio (edit.), Nueve conceptos claves para entender la Convención sobre los Derechos de las Personas con Discapacidad. Lima: Instituto de Democracia y Derechos Humanos (IDEHPUCP), págs. 73-98.

Butler, Judith (2007). El género en disputa. El feminismo y la subversión de la identidad. Barcelona: Paidós.

(2016). Conferencia "Cuerpos que todavía importan” (Videograbación). Buenos Aires: Red Interdisciplinaria de Estudios de Género de la UNTREF. Consultada el 03 de enero de 2016 en https://www.youtube.com/watch?v=UP5xHhz17s\&t=2475s.

Cabral, Mauro y Benzur, Gabriel (2005). Cuando digo intersex. Un diálogo introductorio a la intersexualidad. Cuadernos Pagu, 24, pág. 283304.

Comisión Interamericana de Derechos Humanos (2015). Informe sobre Violencia contra las personas LGTBI.

(2017). Observaciones de la Comisión Interamericana de Derechos Humanos a la solicitud de Opinión Consultiva presentada por Costa Rica.

Comité contra la Tortura (2012). Observación General Nro. 3.

Comité de Derechos Económicos Sociales y Culturales (2009). Observación General Nro. 20.

(2011a). Observaciones finales respecto a Argentina.

(2011b). Observaciones finales sobre el informe periódico de Alemania.

(2014). Observaciones finales sobre el segundo informe periódico de Lituania.

(2016a). Observación General Nro. 22. (2016b). Observación General. Nro. 23. 
Comité de Derechos Humanos (2008). Observaciones finales del Comité de Derechos Humanos respecto a Irlanda.

(2013). Observaciones finales sobre el séptimo informe periódico de Ucrania.

(2014a). Observación General Nro. 35. Artículo 9. Libertad y seguridad personales.

(2014b). Observaciones finales sobre el cuarto informe periódico de Irlanda.

(2016). Observaciones finales sobre el cuarto informe periódico de Eslovaquia.

(2017a). Case of G. V. Australia.

(2017b). Observaciones finales sobre el tercer informe periódico de Serbia.

Comité de los Derechos del Niño (2009). Observación General Nro. 12.

(2013). Observación general Nro. 15.

(2015). Observaciones finales sobre los informes periódicos cuarto y quinto combinados de Chile.

(2016a). Observaciones finales sobre los informes periódicos tercero y cuarto combinados de la República Islámica del Irán.

(2016b) Observaciones finales sobre los informes periódicos tercero a quinto combinados de Nepal.

Comité para la Eliminación de Todas las Formas de Discriminación contra la Mujer (CEDAW) (2010a). Proyecto de Recomendación General Nro. 28.

(2010b). Observaciones finales para Países bajos.

(2010c). Recomendación General Nro. 27.

(2014a). Observaciones finales sobre el séptimo informe periódico de Bélgica.

(2014b). Observaciones finales sobre el séptimo informe periódico de Finlandia.

(2015). Observaciones finales sobre los informes periódicos quinto y sexto combinados de Eslovaquia.

(2017). Observaciones finales sobre el segundo informe periódico de Montenegro.

Corte Interamericana de Derechos Humanos (2012a). Caso Artavia Murillo y otros (Fertilización in vitro) vs. Costa Rica.

(2012b). Caso Fornerón e hija vs. Argentina.

(2012c). Caso Atala Riffo y Niñas Vs. Chile.

(2014). Caso Veliz Franco y otros Vs. Guatemala.

(2015a). Caso Gonzales Lluy y otros Vs. Ecuador.

(2015b). Caso Velásquez Paiz y otros Vs. Guatemala.

(2016a). Caso I.V. vs Bolivia.

(2016b). Caso Duque Vs. Colombia.

(2016c). Opinión Consultiva OC-22/16. Titularidad de derechos de las personas jurídicas en el sistema interamericano de derechos humanos.
(2017). Identidad de género, e igualdad y no discriminación a parejas del mismo sexo. Obligaciones estatales en relación con el cambio de nombre, la identidad de género, y los derechos derivados de un vínculo entre parejas del mismo sexo). Opinión Consultiva OC-24/17.

De Beauvoir, Simone. (2016). El segundo sexo (12va ed.). Buenos Aires: De Bolsillo.

Fausto - Sterling, Anne (2000). La política de género y la construcción de la sexualidad. Barcelona: Melusina.

Foucault, Michel (2014). Historia de la sexualidad. Volumen 1: La voluntad del saber. Buenos Aires: Siglo Veintiuno Editores.

Fuller, Norma. "¿Innato o adquirido?: La polémica de la sexualidad en Freud y Foucault". Revista Peruana de Ciencias Sociales, Vol. 3 (1), pág. 45-65.

Hawkesworth, Mary. (1999). "Confounding gender". Debate feminista. Año 10, vol. 20, pág. 3-48.

Lamas, Marta (1986). "La antropología feminista y la categoría género". Nueva antropología Vol. VIII (30), noviembre, pág. 173-198.

Laqueur, Thomas (1994). La construcción del sexo. Cuerpo y género desde los griegos hasta Freud. Madrid: Ediciones Cátedra.

Maffia, Diana. y Cabral, Mauro (2003). "Los sexos ¿son o se hacen?". En Maffia, Diana (ed.), Sexualidades migrantes. Género y transgénero. Buenos Aires: Feminaria.

Mas Grau, Jorge (2017) "Del transexualismo a la disforia de género en el DSM. Cambios terminológicos misma esencia patologizante". Revista Internacional de Sociología. Vol. 75, abriljunio, pág. 2-18.

Millet, Kate. (1995). Política sexual. Madrid: Ediciones Catedra.

Molina, Cristina (2000). "Debates sobre el género". En AMORÓS, Celia. Feminismo y Filosofía. Madrid: Editorial Síntesis.

Oficina del Alto Comisionado de las Naciones Unidas (2011). Leyes y prácticas discriminatorias y actos de violencia cometidos por personas por su orientación sexual e identidad de género.

(2015). Discriminación y violencia contra las personas por motivos de orientación sexual e identidad de género.

(2016a). Written submission for the Request for an Advisory Opinion submitted by the State of Costa Rica.

(2016b). Living free and equal: What States Are Doing to Tackle Violence and 
La trans-formación del Derecho: La evolución del Derecho Internacional de los Derechos Humanos para proteger la identidad de género de las personas trans

The trans-formation of Law: The evolution of the international human rights law in order to protect the gender identity of transgender people

Discrimination against Lesbian, Gay, Bisexual, Transgender and Intersex People.

Rubin, Gayle (1989). "Reflexionando sobre el sexo: notas para una teoría radical de la sexualidad". En: Varice, Carol (comp). Placer y peligro: explorando la sexualidad femenina. Madrid: Revelación.

Saldivia Menajovsky, Laura (2017). Sobre el derecho a la identidad de género. Ciudad de México: UNAM.

Searle, John (2014). Mente, lenguaje y sociedad. Madrid: Alianza Editorial.

Stoller, Robert (1968). Sex and Gender: On the development of Masculinity and Feminity. Nueva York: Science House.
Tribunal Europeo de Derechos Humanos (1986). Rees v. The United Kindgom.

(1992). Case of B v. France.

Kingdom

(1998). Case of Sheffield and Horsman v. The United

(2002a). Case of Christine Goodwin v. The United Kingdom. (2002b). Case of I. v. The United Kingdom.

(2006). Case of Grant v. The United Kindgom.

(2010). Case of P.V. v. Spain.

(2013) Case of I.G and others v. Slovakia.

(2014). Case of Hämäläinen vs. Finlandia.

(2015). Case of Identoba and others v. Georgia.

(2017). Case of AP., Garçon and Nicot v. France.

\section{Benites, Vargas \& Ugaz \\ ABOGADOS}

